\section{(6) OPEN ACCESS}

\title{
Small incision lenticule extraction (SMILE) and femtosecond laser LASIK: comparison of corneal wound healing and inflammation
}

\author{
Zixian Dong, ${ }^{1}$ Xingtao Zhou, ${ }^{1}$ Jihong Wu, ${ }^{1}$ Zhehuan Zhang, ${ }^{1}$ Tao Li, ${ }^{1}$ Zimei Zhou, ${ }^{2}$ \\ Shenghai Zhang, ${ }^{1}$ Gang Li ${ }^{1}$
}

${ }^{1}$ Institute of Ophthalmology, Eye and ENT Hospital, Fudan University, Shanghai, PR China ${ }^{2}$ Department of

Ophthalmology, Bronx Lebanon Hospital Center, Bronx, New York, USA

\section{Correspondence to} Dr Xingtao Zhou, Eye and ENT Hospital, Fudan University, 83 Fenyang Road, Shanghai 200031, PR China; xingtaozhou@163.com

Received 17 March 2013 Revised 11 September 2013 Accepted 12 October 2013 Published Online First 13 November 2013
ABSTRACT

Aim To evaluate and compare early corneal wound healing and inflammatory responses after small incision lenticule extraction (SMILE) versus femtosecond laser laser in situ keratomileusis (LASIK).

Methods Thirty-six eyes of 36 rabbits underwent SMILE, while another 36 eyes of 36 rabbits were treated with femtosecond laser LASIK. All the eyes were subjected to the same refractive correction of $-6.00 \mathrm{DS} /-1.00 \mathrm{DC}$. Twelve eyes that had no surgery were included for control. After euthanisation, corneal tissue sections were evaluated with terminal deoxyribonucleotidyl transferasemediated dUTP-digoxigenin nick-end labelling (TUNEL) assay to detect apoptosis at postoperative 4 and $24 \mathrm{~h}$, immunocytochemistry for Ki67 to detect keratocyte proliferation at postoperative day 3, week 1 and month 1 , and immunocytochemistry for CD11b to detect inflammation at postoperative day 1, day 3 and week 1 , respectively.

Results No adverse effects were noted after SMILE or LASIK. Corneal healing postoperatively was uneventful in all cases. There were significantly fewer TUNEL-positive corneal stromal cells after the SMILE procedure at 4 and $24 \mathrm{~h}$ postoperatively $(p<0.01)$ compared with the LASIK procedure. In addition, immunocytochemistry showed significantly fewer Ki67-positive cells in the SMILE group than those in the femtosecond laser LASIK group at day 3 and week 1 postoperatively $(p<0.05)$, but there was little expression of Ki67 at month 1 postoperatively in both groups. The CD11b-positive cells were significantly fewer in the SMILE group at day 1, day 3 and week 1 postoperatively $(p<0.01)$.

Conclusions SMILE induces less keratocyte apoptosis, proliferation and inflammation compared with femtosecond laser LASIK.

The femtosecond laser can increase the safety, efficiency, precision and versatility of the lamellar incision. ${ }^{1}$ This novel technology has been largely applied in the creation of corneal flaps in laser in situ keratomileusis (LASIK). Recently, the femtosecond laser has also been used to create an intrastromal refractive lenticule, which is regarded as refractive lenticule extraction (ReLEx). ${ }^{2}$ ReLEx can be further divided into femtosecond lenticule extraction (FLEx) and small incision lenticule extraction (SMILE), based on how the lenticle is removed. The former allows creating and lifting corneal flaps followed by the lenticule extraction, while in SMILE, the lenticle is removed directly via a small incision. It is believed that SMILE is likely to have better corneal biomechanical stability postoperatively and further studies are required to support this clinical observation.

Corneal wound healing may have a major impact on the biomechanical stability postoperatively. Previously, Kim et $a l^{3}$ found inflammatory cell infiltration in rabbit corneas was significantly greater after the flap creation by an initial femtosecond laser than that by a mechanical microkeratome at 4 and $24 \mathrm{~h}$ postoperatively. A similar observation by Netto $e t a l^{4}$ revealed that LASIK flaps formed with a femtosecond laser of higher energy levels $(15 \mathrm{KHz})$ may result in more keratocyte cell death, more severe cell inflammation and proliferation compared with flaps using a microkeratome or a femtosecond laser of lower energy levels (30 or $60 \mathrm{KHz}$ ). Results of the $60 \mathrm{KHz}$ laser and microkeratome were not significantly different for any of the parameters at $24 \mathrm{~h}$. At present, however, few reports of the corneal wound-healing process of ReLEx have been published. The purpose of this study was to evaluate early corneal wound healing and inflammatory responses after SMILE and femtosecond laser-assisted (fs-LASIK).

\section{MATERIALS AND METHODS}

\section{Animals and study design}

The study adhered to the tenets of the Association for Research in Vision and Ophthalmology Statement for the Use of Animals in Ophthalmic and Vision Research and was approved by the Animal Control Committee at Eye and ENT Hospital, Fudan University. A total of $72 \mathrm{New}$ Zealand White rabbits (with body weights of approximately $3.0 \mathrm{~kg}$ ) were included. All animals were healthy and free of clinically observable ocular disease. The animals were randomly divided into two groups (36 rabbits in each group) for SMILE or fs-LASIK procedure. One eye of each rabbit was selected randomly for surgery. Twelve eyes that had no surgery were included for control.

Animals were premedicated with a subcutaneous injection of diazepam and atropine $(1 \mathrm{mg})$ and anesthetised with ketamine hydrochloride $(35 \mathrm{mg} / \mathrm{kg}$ intramuscularly). For additional local anaesthesia, oxybuprocaine $0.4 \%$ drops were instilled into the operated eyes. The SMILE and fs-LASIK procedure were performed by a single surgeon (ZXT) and all eyes were subjected to the same refractive correction of $-6.00 \mathrm{DS} /-1.00 \mathrm{DC}$. Postoperative medications included topical antibiotics (tobramycin $0.3 \%$ drops, three times/day) and steroidal anti-inflammatory drugs (fluorometholone $0.1 \%$ drops, four times/day) for 1 week. 
Postoperative corneal healing was observed routinely to exclude the possibility of postoperative complications by slit lamp microscopy. The terminal deoxyribonucleotidyl transferase-mediated dUTP-digoxigenin nick-end labelling (TUNEL) assay was used to detect apoptotic cells at 4 and $24 \mathrm{~h}$ after surgery. Immunofluorescent assays were performed to observe the expression of Ki67, a cell marker of the G1-M phase of mitosis, at postoperative day 3, week 1 and month 1. In addition, CD11b, a marker of monocytes, was tested at postoperative day 1 , day 3 and week 1 . Six corneal samples were obtained for histological analysis at each time point.

\section{The procedure}

\section{SMILE procedure}

The intrastromal refractive lenticule was created by a $500 \mathrm{kHz}$ femtosecond laser (VisuMax, Carl Zeiss Meditec, Jena, Germany) and the energy density was approximately $130 \mathrm{~nJ}$. The femtosecond incisions were performed in the following sequence $^{5}$ : the posterior surface of the lenticule, the lenticule border, the anterior surface of the lenticule and the side cut incision for the access to the lenticule. The lenticule diameter was set at $5.5 \mathrm{~mm}$ and the stromal cap was completed at $100 \mu \mathrm{m}$ depth, $6.5 \mathrm{~mm}$ diameter centred at the pupil. The side cut was set at $3.5 \mathrm{~mm}$ width and located in the 12 o'clock position. After the femtosecond laser cutting procedure, a thin spatula was inserted via the side-cut incision to make the blunt dissection of intrastromal lenticule. The refractive lenticule was then grasped with forceps and extracted from the cornea. The intrastromal pocket was then flushed with a balanced salt solution.

\section{fs-LASIK procedure}

The same femtosecond laser was used to create a stromal flap with an upper hinge at $100 \mu \mathrm{m}$ corneal depth, $7 \mathrm{~mm}$ diameter

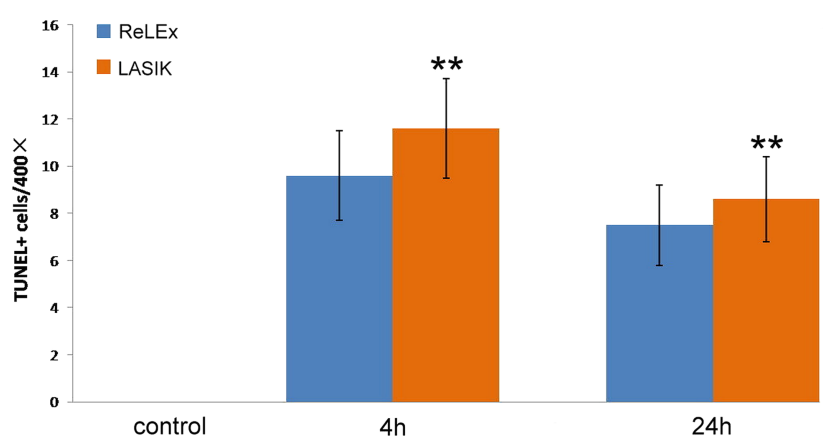

Figure 2 A bar graph showing the number of transferase-mediated dUTP-digoxigenin nick-end labelling (TUNEL)-positive cells in the central cornea at different time points postoperatively. The refractive lenticule extraction (ReLEx) group had significantly fewer

TUNEL-positive cells at 4 and $24 \mathrm{~h}$ after surgery compared with the laser in situ keratomileusis (LASIK) group. ${ }^{*} \mathrm{p}<0.01$.

centred at the pupil. The energy density was approximately $185 \mathrm{~nJ}$. After lifting the flap, the underlying stroma received refractive corrections of $-6.00 \mathrm{DS} /-1.00 \mathrm{DC}$ by using an excimer laser (MEL 80; Carl Zeiss Meditec). Its fluence was $180 \mathrm{~mJ} / \mathrm{cm}^{2}$ at a frequency of $250 \mathrm{~Hz}$. The optical zone diameter was $5.5 \mathrm{~mm}$ and the transition zone diameter was $1.0 \mathrm{~mm}$ larger than the optical zone diameter in all cases. The corneal stromal bed was flushed with a balanced salt solution. The flap was then repositioned and sutured in the 5 and 7 o'clock position using a 10-0 nylon line.

\section{Tissue fixation and sectioning}

The corneas of operated and control eyes were harvested from the globe. The corneas were embedded in liquid OCT compound (Leica Microsystems, Germany). The frozen tissue blocks
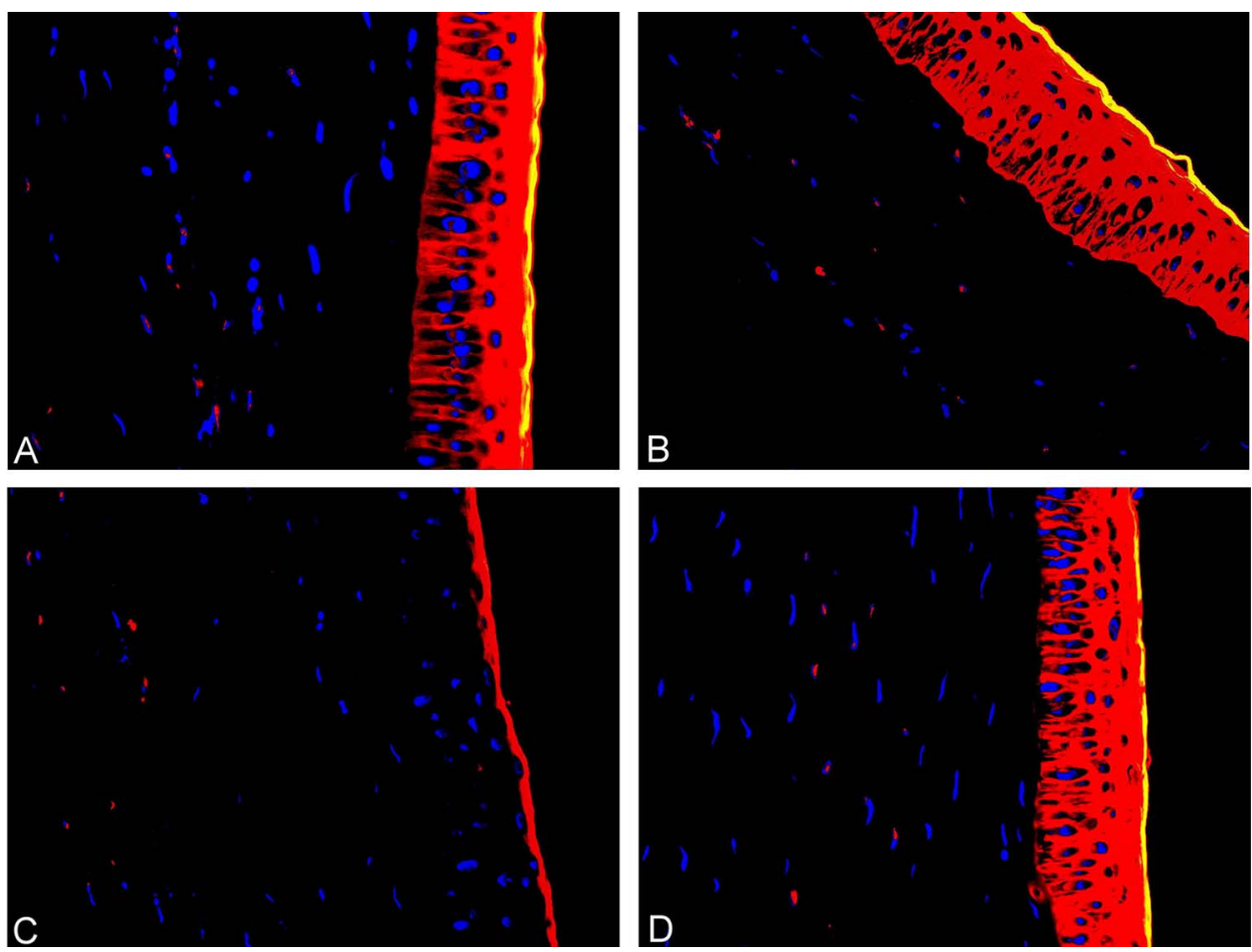

Figure 1 Transferase-mediated dUTP-digoxigenin nick-end labelling (TUNEL) assay of the central cornea of different groups postoperatively. (A) $4 \mathrm{~h}$ after laser in situ keratomileusis (LASIK). (B) $4 \mathrm{~h}$ after refractive lenticule extraction (ReLEx). (C) $24 \mathrm{~h}$ after LASIK. (D) $24 \mathrm{~h}$ after ReLEx (original magnification $\times 400$ ). 
were stored at $-80^{\circ} \mathrm{C}$ until sectioning. Central corneal sections (10 $\mu \mathrm{m}$ thickness) were cut using a cryostat (Leica CM 3050S, Germany). Sections were air dried and maintained at $-80^{\circ} \mathrm{C}$ until staining.

\section{Biological analysis}

TUNEL assay

To detect fragmentation of DNA associated with apoptosis, tissue sections were fixed in acetone at $-20^{\circ} \mathrm{C}$ for $2 \mathrm{~min}$, dried
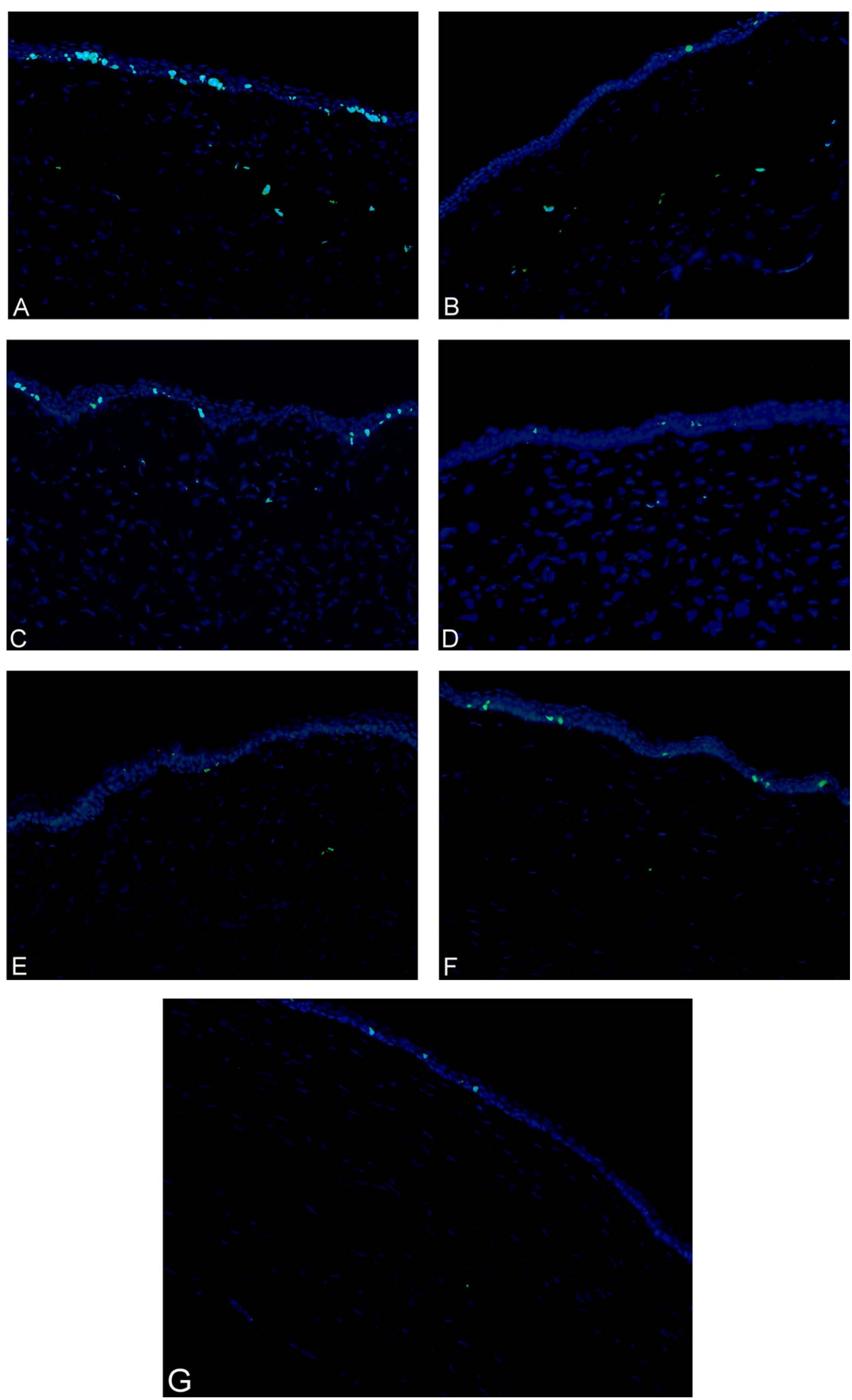

Figure 3 Immunohistochemical staining for Ki67 of the central cornea of different groups postoperatively. (A) 3 days after laser in situ keratomileusis (LASIK). (B) 3 days after refractive lenticule extraction (ReLEx). (C) 1 week after LASIK. (D) 1 week after ReLEx. (E) 1 month after LASIK. (F) 1 month after ReLEx. (G) The control group (original magnification $\times 200$ ). 
at room temperature for $5 \mathrm{~min}$, and subsequently placed in balanced salt solution. A fluorescence-based TUNEL assay (ApopTag, Cat. No. S7165; Intergen Corp, USA) was performed according to the manufacturer's instructions. Negative controls (sections from unwounded corneas) were included in each assay.

\section{Immunocytochemistry assays}

Sections was incubated with either mouse monoclonal antibody against CD11b (Thermo Corp, USA) diluted 1:100 or with mouse monoclonal antibody against Ki67 (DAKO Corp, Denmark) diluted $1: 100$ for $1.5 \mathrm{~h}$ at $37^{\circ} \mathrm{C}$. The secondary antibodies, fluorescein-conjugated goat anti-mouse IgG (Kangcheng Corp, China) diluted 1:800, was applied for $30 \mathrm{~min}$ at $37^{\circ} \mathrm{C}$. Slides were mounted with medium containing $4^{\prime}, 6$ diamidino-2phenylindole (Thermo) to observe all cell nuclei in the tissue. Negative controls with secondary antibody alone were included.

Photographs were obtained with a fluorescence microscope (Leica DM 4000B, Germany). All of the stained cells in seven non-overlapping, full-thickness columns from the anterior to the posterior stromal surface were counted. The columns where counts were performed were randomly selected from the central cornea of each specimen.

\section{Statistical analysis}

Statistical analysis was performed using Microsoft Excel 2007 (Microsoft; Redmond, Washington DC, USA) and SPSS V.13.0 software (SPSS Inc, Chicago, Illinois, USA). Comparisons between the two groups at each time point were performed using one-way analysis of variance (ANOVA). When the ANOVA normality assumption was incorrect by the Kolmogorov-Smirnov test, the non-parametric Mann-Whitney $\mathrm{U}$ test was used. A p value $<0.05$ was considered statistically significant.

\section{RESULTS}

No adverse effects were noted during the SMILE and fs-LASIK procedure. The slit lamp biomicroscopy showed a little oedema of the corneas within 1 week in both groups. All rabbits could open their eyes naturally and resume their daily activities within 1 day postoperatively. No infection or diffuse lamellar keratitis was noticed during the corneal healing process.

\section{TUNEL outcomes}

All corneas that underwent the SMILE or fs-LASIK procedure had TUNEL-positive cells at the interface in the central stroma at 4 and $24 \mathrm{~h}$ postoperatively (figure 1 ). There were significantly fewer TUNEL-positive stromal cells in corneas in the SMILE group at each time point $(p<0.01)$. No TUNEL-positive stromal cells were identified in control corneas. Quantitative analysis of the number of TUNEL-positive cells in the central corneal stroma is depicted in figure 2 .

\section{Immunohistochemisty outcomes}

Both groups displayed Ki67-positive cells in the stroma at postoperative day 3 and week 1, but there was little expression of Ki67 at 1 month postoperatively (figure 3 ). The SMILE group showed fewer Ki67-positive cells when compared with the fs-LASIK group at day 3 and week 1 postoperatively $(\mathrm{p}<0.05)$. No Ki67-positive stromal cells were detected in control corneas. Quantitative analysis of the number of Ki67-positive cells in the central corneal stroma is shown in figure 4. In addition, the CD11b-positive cells were significantly fewer in the SMILE group at day 1, day 3 and week 1 postoperatively (figure 5) $(p<0.01)$. There were no CD11b-positive stromal cells in

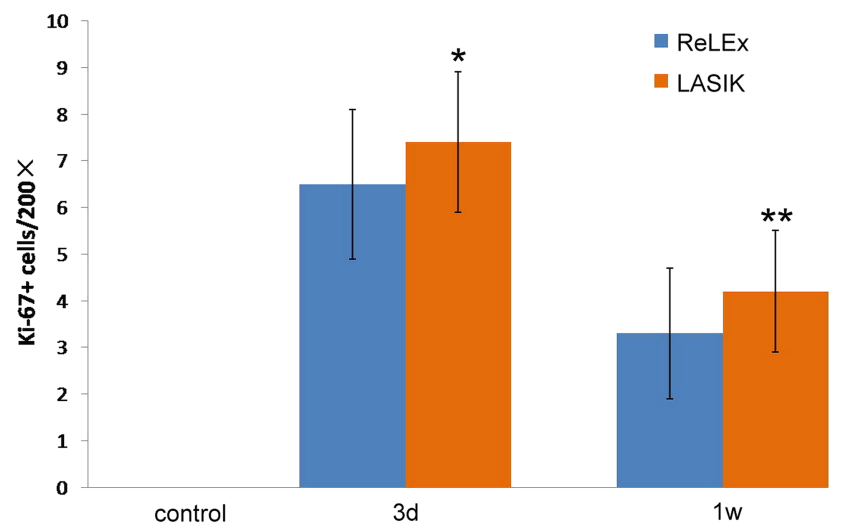

Figure 4 A bar graph showing the number of Ki67-positive cells in the central cornea at 3 days, 1 week and 1 month postoperatively. The refractive lenticule extraction (ReLEx) group had significantly fewer Ki67-positive cells at each time point after surgery compared with the laser in situ keratomileusis (LASIK) group. ${ }^{*} p<0.05,{ }^{* *} p<0.01$.

control corneas. Figure 6 depicts the quantification of the number of CD11b-positive cells in the central corneal stroma.

\section{DISCUSSION}

It has been accepted that the corneal wound-healing response after refractive surgical procedures is a remarkably complex cascade. $^{6}$ Epithelial injury triggers release of various kinds of cytokines and growth factors, ${ }^{7-10}$ including interleukin (IL)-1, tumour necrosis factor (TNF)- $\alpha$, epidermal growth factor and platelet-derived growth factor. These cytokines directly induce keratocyte apoptosis, hence initiating the complex cascading response. Surrounding live keratocytes are activated and transformed into fibroblasts or myofibroblasts, and migrate to repopulate the depleted stroma. Meanwhile, chemokines released from the epithelium or keratocytes would attract inflammatory cells, including monocytes, granulocytes and lymphocytes, into the corneal stroma to phagocytise the apoptotic and necrotic debris. Subsequently, the remodelling of the extracellular matrix and the stroma was achieved by myofibroblasts through production of collagen, glycosaminoglycans, collagenases, gelatinases and matrix metalloproteinases. ${ }^{11}$ Clinically, it has been reported by several studies that SMILE could make the correction of ametropia with safety, efficacy, predictability and stability $^{12}{ }^{13}$ However, few reports have been published on the wound-healing and inflammatory responses after SMILE. In the present study, we demonstrated SMILE could induce less keratocyte apoptosis, proliferation and inflammation compared with fs-LASIK.

The ReLEx and fs-LASIK procedures make a refractive correction via different mechanisms. The ReLEx procedure involves intrastromal dissection using a femtosecond laser followed by tissue extraction, while fs-LASIK allows the stroma ablation by an excimer laser. As we know, the excimer laser uses ultraviolet light to break molecular bonds in the corneal stroma, whereas the femtosecond laser is a near-infrared laser making the photodisruption of stromal tissue with less tissue injury. Moreover, creating and lifting corneal flaps is necessary in fs-LASIK and FLEx, ${ }^{14} 15$ but not in SMILE. Thus, SMILE may stimulate less inflammatory reaction and cell death compared with fs-LASIK.

It has been demonstrated that the keratocyte apoptosis peaks at approximately $4 \mathrm{~h}$ after epithelial injury and may last till 1 week after the initial insult. ${ }^{16}$ Both 4 and 24 h postoperatively were the common time points chosen to evaluate the stromal 

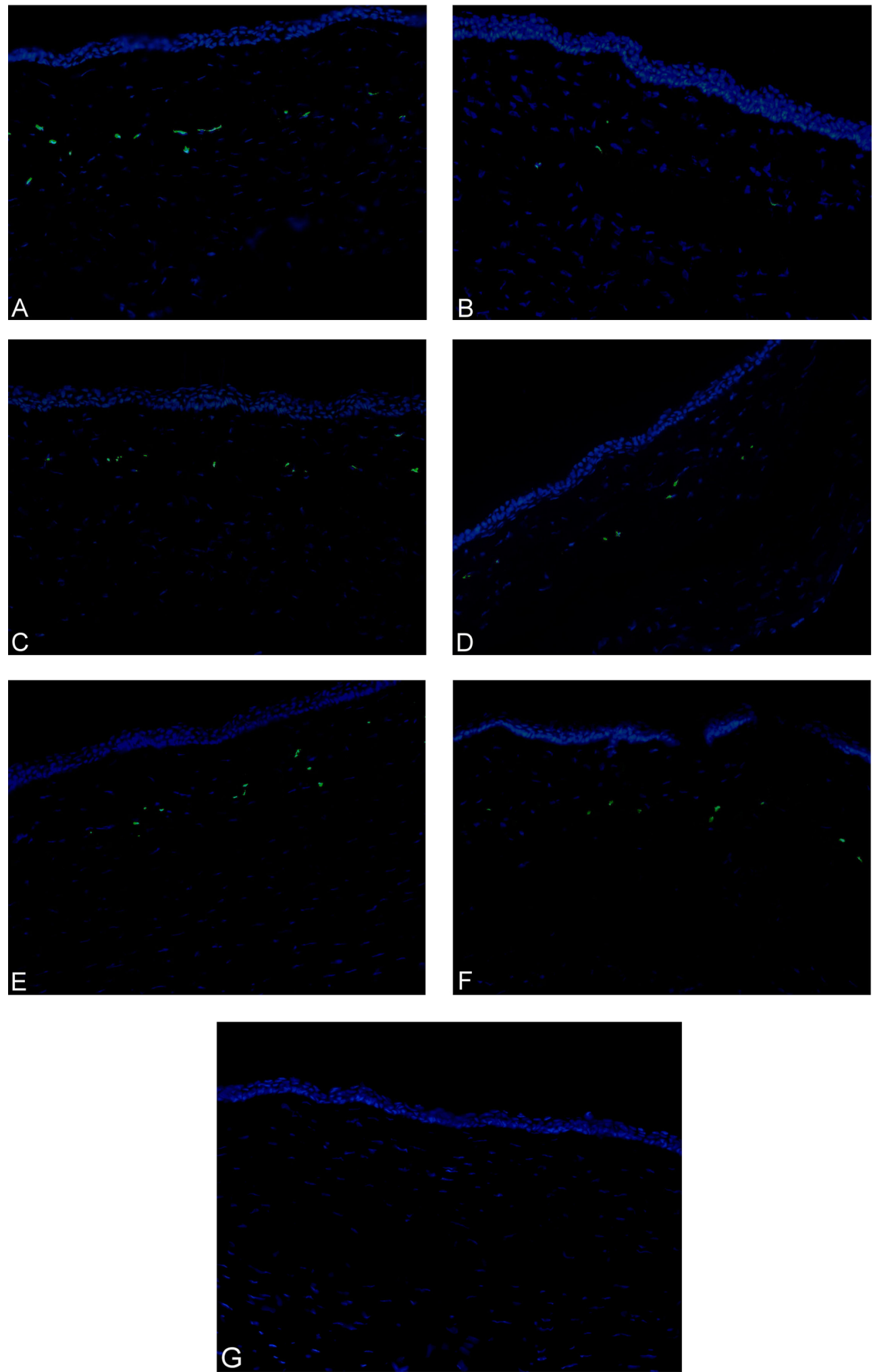

Figure 5 Immunohistochemical staining for CD11b of the central cornea of different groups postoperatively. (A) 1 day after laser in situ keratomileusis (LASIK). (B) 1 day after refractive lenticule extraction (ReLEx). (C) 3 days after LASIK. (D) 3 days after ReLEx. (E) 1 week after LASIK. (F) 1 week after ReLEx. (G) The control group (original magnification $\times 200$ ).

cell death in previous studies. ${ }^{17} 18$ In our study, TUNEL-positive cells were detected at the interface after SMILE and fs-LASIK procedures at postoperative 4 and $24 \mathrm{~h}$. The distribution of apoptotic cells, mediated by proinflammatory cytokines such as IL-1 and TNF $\alpha$ after epithelial trauma, was determined by the principle of the procedures. ${ }^{19}$ It has been documented that apoptotic cells were located near the interface after LASIK, while TUNEL-positive cells could be observed at the superficial stroma after surface ablation procedures. ${ }^{20}$ SMILE and fs-LASIK involve the creation of a corneal cap or flap, which facilitates 


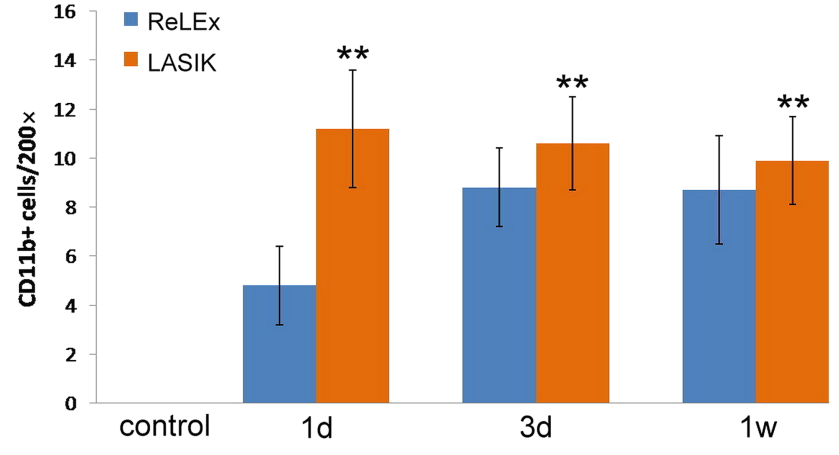

Figure 6 A bar graph showing the number of CD11b-positive cells in the central cornea at 1 day, 3 days and 1 week postoperatively. The refractive lenticule extraction (ReLEx) group had significantly fewer CD11b-positive cells at each time point after surgery compared with the laser in situ keratomileusis (LASIK) group. ${ }^{* *} p<0.01$.

the dispersion of cytokines at the interface via tear and epithelial debris. As a result, more severe damage would occur close to the lamellar interface after both procedures. However, fs-LASIK also exerts an excimer ablation effect in addition to the femtosecond laser dissection compared with SMILE. Furthermore, SMILE would induce less epithelial trauma by small incision and less contact with cytokines for free of lifting the cap. All these factors may play a role, which results in fewer TUNEL-positive stromal cells in the SMILE group than in the fs-LASIK group $(\mathrm{p}<0.01)$.

The expression of Ki67 can be used to indicate the keratocyte proliferation that begins within $12-24 \mathrm{~h}$ after epithelial injury. Mohan et $a l^{21}$ compared the expression of Ki67 in rabbit eyes following LASIK compared with that following photorefractive keratectomy during 3 months postoperatively. The Ki67-positive cells can be detected significantly at day 3 and week 1 in the LASIK group. In this study, Ki67-positive cells in the SMILE group were significantly fewer than those in the fs-LASIK group at postoperative day 3 and week $1(\mathrm{p}<0.05)$, indicating that SMILE may stimulate less keratocyte proliferation. Our data are consistent with previous findings in post-FLEx eyes reported by Riau et $a l^{22}$ Besides, there was little expression of Ki67 in both groups at month 1 after surgery, indicating both SMILE and fs-LASIK can initiate mild proliferation.

Also, immunohistochemical testing for the antibody anti-CD11b was used to identify the expression of monocytes that play a major role in inflammatory infiltration 8-24 h after injury. O'Brien et $a l^{23}$ studied the inflammatory response in early 1 week after excimer laser keratectomy and reported that macrophages may contribute to transient corneal haze postoperatively. Santhiago et $a l^{24}$ reported that significantly more CD11b-positive cells were noted in the stroma after intracorneal inlay implantation compared with the control group at 24 and $48 \mathrm{~h}$ postoperatively in rabbits $(\mathrm{p}<0.05)$. In our study, CD11b-positive monocyte mediated inflammation was significantly less severe in postoperative week 1 in the SMILE group compared with the fs-LASIK group. We hypothesise that this could be due to the following reasons: a small incision for the lenticule extraction will produce fewer chemokines to attract inflammatory cells in the injury; the intrastromal dissection by a femtosecond laser contributes to reduced tissue injury compared with the stroma ablation by an excimer laser; there was less necrotic debris in the interface after ReLEx.

The femtosecond laser energy level may have an impact on the extent of corneal cell death and inflammatory response after flap formation by a femtosecond laser. ${ }^{25}$ Previously, Netto et al ${ }^{4}$ found that rabbit corneas that had flaps formed by the $15 \mathrm{KHz}$ laser had more stromal cell death, greater stromal cell proliferation and greater monocyte influx in the cornea at $24 \mathrm{~h}$ after surgery than corneas that had flaps formed with the 30 or $60 \mathrm{KHz}$ laser. Similarly, de Medeiros et $a l^{26}$ reported that higher energy levels can trigger more cell death and inflammatory infiltration when the femtosecond laser is used to create corneal flaps. The energy density of the VisuMax femtosecond laser in our study was $130 \mathrm{~nJ}$ for the lenticule and $185 \mathrm{~nJ}$ for the flap at a repetition rate of $500 \mathrm{kHz}$. This may induce mild keratocyte apoptosis and corneal inflammation.

In summary, our animal study showed that ReLEx induces a lower degree of keratocyte apoptosis, proliferation and inflammation compared with fs-LASIK. Further studies are needed to evaluate whether this novel procedure may induce less postoperative regression.

Contributors ZD and XZ: design and conduction of the study; ZD, XZ, JW, ZZ, TL, ZZ, SZ and GL: data analysis and interpretation; ZD: manuscript preparation; JW, ZZ, TL, ZZ, SZ and GL: manuscript review; XZ and JW: final approval of the manuscript.

Funding Supported in part by National Natural and Science Program Grant A040413 and Pudong Science and Technology Development and Innovation fund Grant PKJ2009-Y01.

\section{Competing interests None.}

Provenance and peer review Not commissioned; externally peer reviewed.

Open Access This is an Open Access article distributed in accordance with the Creative Commons Attribution Non Commercial (CC BY-NC 3.0) license, which permits others to distribute, remix, adapt, build upon this work non-commercially, and license their derivative works on different terms, provided the original work is properly cited and the use is non-commercial. See: http://creativecommons.org/ licenses/by-nc/3.0/

\section{REFERENCES}

1 Soong HK, Malta JB. Femtosecond lasers in ophthalmology. Am J Ophthalmol 2009:147:189-97.

2 Kim P, Sutton GL, Rootman DS. Applications of the femtosecond laser in corneal refractive surgery. Curr Opin Ophthalmol 2011;22:238-44.

$3 \mathrm{Kim} \mathrm{JY,} \mathrm{Kim} \mathrm{MJ,} \mathrm{Kim} \mathrm{TI,} \mathrm{et} \mathrm{al.} \mathrm{A} \mathrm{femtosecond} \mathrm{laser} \mathrm{creates} \mathrm{a} \mathrm{stronger} \mathrm{flap} \mathrm{than} \mathrm{a}$ mechanical microkeratome. Invest Ophthalmol Vis Sci 2006;47:599-604.

4 Netto MV, Mohan RR, Medeiros FW, et al. Femtosecond laser and microkeratome corneal flaps: comparison of stromal wound healing and inflammation. I Refract Surg 2007;23:667-76.

5 Vestergaard A, Ivarsen AR, Asp S, et al. Small-incision lenticule extraction for moderate to high myopia: predictability, safety, and patient satisfaction. J Cataract Refract Surg 2012;38:2003-10.

6 Dupps WJ Jr, Wilson SE. Biomechanics and wound healing in the cornea. Exp Eye Res 2006:83:709-20.

7 Tuominen IS, Tervo TM, Teppo AM, et al. Human tear fluid PDGF-BB, TNF-alpha and TGF-beta1 vs corneal haze and regeneration of corneal epithelium and subbasal nerve plexus after PRK. Exp Eye Res 2001;72:631-41.

8 Wilson SE, He YG, Weng J, et al. Epithelial injury induces keratocyte apoptosis: hypothesized role for the interleukin-1 system in the modulation of corneal tissue organization and wound healing. Exp Eye Res 1996;62:325-7.

9 Mohan RR, Mohan RR, Kim WJ, et al. Modulation of TNF-alpha induced apoptosis in corneal fibroblasts by transcription factor NF-kb. Invest Ophthalmol Vis Sci 2000:41:1327-34.

10 Wilson SE, Chen L, Mohan RR, et al. Expression of HGF, KGF, EGF and receptor messenger RNAs following corneal epithelial wounding. Exp Eye Res 1999;68:377-97.

11 Funderburgh JL, Mann MM, Funderburgh ML. Keratocyte phenotype mediates proteoglycan structure: a role for fibroblasts in corneal fibrosis. J Biol Chem 2003:278:45629-37.

12 Shah R, Shah S, Sengupta S. Results of small incision lenticule extraction: all-in-one femtosecond laser refractive surgery. J Cataract Refract Surg 2011;37:127-37.

13 Sekundo W, Kunert KS, Blum M. Small incision corneal refractive surgery using the small incision lenticule extraction (SMILE) procedure for the correction of myopia and myopic astigmatism: results of a 6 month prospective study. $\mathrm{Br} J$ Ophthalmol 2011;95:335-9

14 Sekundo W, Kunert K, Russmann C, et al. First efficacy and safety study of femtosecond lenticule extraction for the correction of myopia: six-month results. J Cataract Refract Surg 2008:34:1513-20. 
15 Blum M, Kunert K, Schröder M, et al. Femtosecond lenticule extraction for the correction of myopia: preliminary 6-month results. Graefes Arch Clin Exp Ophthalmol 2010:248:1019-27.

16 Netto MV, Mohan RR, Ambrósio R Jr, et al. Wound healing in the cornea: a review of refractive surgery complications and new prospects for therapy. Cornea 2005;24:509-22

17 Song JS, Kim JH, Yang M, et al. Mitomycin- $\mathrm{C}$ concentration in cornea and aqueous humor and apoptosis in the stroma after topical mitomycin-C application: effects of mitomycin-C application time and concentration. Cornea 2007;26:461-7.

18 Netto MV, Mohan RR, Sinha S, et al. Effect of prophylactic and therapeutic mitomycin $\mathrm{C}$ on corneal apoptosis, cellular proliferation, haze, and long-term keratocyte density in rabbits. J Refract Surg 2006;22:562-74.

19 Wilson SE, Netto M, Ambrósio R Jr. Corneal cells: chatty in development, homeostasis, wound healing, and disease. Am J Ophthalmol 2003;136:530-6.

20 Wilson SE, Kim W-J. Keratocyte apoptosis: implications on corneal wound healing, tissue organization, and disease. Invest Ophthalmol Vis Sci 1998:39:220-6.
21 Mohan RR, Hutcheon AE, Choi R, et al. Apoptosis, necrosis, proliferation, and myofibroblast generation in the stroma following LASIK and PRK. Exp Eye Res 2003;76:71-87

22 Riau AK, Angunawela RI, Chaurasia SS, et al. Early corneal wound healing and inflammatory responses after refractive lenticule extraction (ReLEX). Invest Ophthalmol Vis Sci 2011;52:6213-21.

23 O'Brien TP, Li Q, Ashraf MF, et al. Inflammatory response in the early stages of wound healing after excimer laser keratectomy. Arch Ophthalmol 1998:116:1470-4.

24 Santhiago MR, Barbosa FL, Agrawal V, et al. Short-term cell death and inflammation after intracorneal inlay implantation in rabbits. J Refract Surg 2012;28:144-9.

25 Santhiago MR, Wilson SE. Cellular effects after laser in situ keratomileusis flap formation with femtosecond lasers: a review. Cornea 2012;31:198-205.

26 de Medeiros FW, Kaur H, Agrawal V, et al. Effect of femtosecond laser energy level on corneal stromal cell death and inflammation. J Refract Surg 2009;25:869-74. 